\title{
PENGARUH MOTIVASI DAN KOMPETENSI TERHADAP KINERJA KARYAWAN DAN KUALITAS LAYANAN PADA RUMAH MAKAN AYAM BAKAR WONG SOLO
}

\author{
Siti Mardah \\ Universitas Islam Kalimatan MAB \\ Jl. Adhyaksa No. 2 Kayu Tangi, Banjarmasin, Kalimantan Selatan \\ e-mail: siti.mardah83@gmail.com
}

\begin{abstract}
This study discusses how human resources play a vital role in the activities of any organization including business activities in the face of globalization era, including the management of restaurant Ayam Bakar Wong Solo. This research using the method "Cross Sectional". Sampling is done by stratified random sampling with the number of samples studies are 100 respondent. The research results are motivation and competence affects the service quality of Ayam Bakar Wong Solo Restaurant employees directly and indirectly through performance variable.
\end{abstract}

Keywords: motivation, competence, performance, service quality

\begin{abstract}
Abstrak: Penelitian ini membahas bagaimana sumber daya manusia sangat berperan dalam kegiatan organisasi apapun termasuk kegiatan bisnis dalam menghadapi era globalisasi, termasuk dalam pengelolaan rumah makan Ayam Bakar Wong Solo. Penelitian ini menggunakan metode "Cross Sectional". Metode pengambilan sampel yang digunakan dilakukan secara stratifikasi proporsional random sampling dengan jumlah sampel yang diteliti sebanyak 100 responden. Hasil Penelitian menemukan bahwa motivasi dan kompetensi mempengaruhi kualitas pelayanan rumah makan Ayam Bakar Wong Solo, baik secara langsung ataupun secara tidak langsung melalui variabel kinerja.
\end{abstract}

Kata Kunci : motivasi, kompetensi, kinerja, kualitas layanan

\section{Latar Belakang}

Indonesia adalah negara yang sedang berkembang di berbagai bidang khususnya dalam bidang ekonomi, salah satunya ialah perkembangan bisnis jasa boga. Seiring dengan perkembangan pengetahun, diversifikasi pekerjaan dan tempat kerja masyarakat Banjarmasin maka keberadaan rumah makan sebagai pengelola makanan merupakan tuntutan kebutuhan masyarakat. Hal ini memancing banyak investor untuk melakukan bisnis jasa boga terutama rumah makan semakin berkembang di Banjarmasin. Sumber daya manusia sangat berperan dalam segala kegiatan organisasi apapun termasuk kegiatan bisnis dalam menghadapi era globalisasi sekarang ini. Oleh karena itu pengelola rumah makan dihadapkan untuk tidak saja mampu menjual produk dan jasanya, melainkan juga harus terus melakukan perbaikan pada sumber daya manusia tersebut, yaitu dengan meningkatkan motivasi terhadap karyawan serta kompetensi untuk lebih produktif dalam pekerjaannya, dan untuk menemukan cara-cara baru dalam melakukan peningkatan kinerja karyawan.

Salah satu rumah makan yang saat ini sedang berkembang dengan sistem waralabanya adalah Rumah Makan Ayam Bakar Wong Solo. Rumah Makan Ayam Bakar Wong Solo ini pertama berdiri pada tahun 1991 di Medan dan mulai membuka cabang di Banjarmasin pada tahun 2004. 
Tabel 1. Pengunjung Rumah Makan Ayam Bakar Wong Solo Tahun 2009-2013

\begin{tabular}{cccc}
\hline Tahun & Pengunjung & Perkembangan & \% \\
\hline 2009 & 126.000 & - & - \\
\hline 2010 & 127.000 & 1.000 & 0,79 \\
\hline 2011 & 128.000 & 1.000 & 0,79 \\
\hline 2012 & 128.500 & 500 & 0,39 \\
\hline 2013 & 128.700 & 200 & 0,15 \\
\hline
\end{tabular}

Sumber : Rumah Makan Ayam Bakar Wong Solo

Sebuah organisasi keberhasilannya sangat tergantung pada kemampuan pimpinan (manager) dalam mengorganisasikan karyawan dimana harus memperhatikan kemauan dan kemampuan karyawan dalam memenuhi target yang ditetapkan. Usaha yang dilakukan manusia dengan sendirinya mempengaruhi perilaku individu, termasuk di dalamnya motivasi dalam bekerja dan kompetensi yang dibutuhkan untuk menyelesaikan suatu pekerjaan.

Berdasarkan pada latar belakang tersebut, penelitian ini berupaya untuk mencari kekuatan pengaruh dari motivasi dan kompetensi terhadap kinerja dan kualitas pelayanan di Rumah Makan Ayam Bakar Wong Solo.

\section{Kajian Literatur}

Motivasi menurut Velthzal Rivai (2003) adalah serangkaian dan nilai-nilai yang mempengaruhi individu untuk mencapai hal yang spesifik sesuai dengan tujuan individu. Sikap dan nilai tersebut merupakan suatu yang invisible yang memberikan kekuatan untuk mendorong individu bertingkah laku dalam mencapai tujuan. Pada dasarnya motivasi dapat memacu karyawan untuk bekerja keras sehingga dapat mencapai tujuan mereka. Hal ini akan meningkatkan produktivitas kerja karyawan sehingga berpengaruh pada pencapaian tujuan organisasi. Sumber motivasi ada 3 (tiga) faktor yakni (1) kemungkinan untuk berkembang, (2) jenis pekerjaan dan (3) apakah mereka dapat merasa bangga menjadi bagian dari organisasi tempat mereka bekerja.

Kompetensi menurut Velthzal Rivai (2004:277) adalah kemampuan seseorang merujuk ke suatu kapasitas individu untuk mengerjakan berbagai tugas dalam suatu pekerjaan dan seluruh kemampuan seorang individu pada hakekatnya tersusun dalam dua perangkat faktor, yaitu :

1. Kemampuan intelektual

Kemampuan intelektual seseorang berhubungan dengan tingkat IQ (Intellegence Quotient) atau menyangkut kecerdasan dalam hal pengetahuan. Selain itu juga berhubungan dengan EQ (Emotional Quotient) atau kecerdasan emosional.

2. Kemampuan fisik

Kemampuan fisik memiliki makna penting khususnya untuk melakukan pekerjaan yang kurang menuntut keterampilan. Misalnya pekerjaan yang menuntut stamina, kecekatan tangan, atau bakat.

Kinerja (prestasi kerja) adalah hasil kerja secara kualitas dan kuantitas yang dicapai oleh seseorang pegawai dalam melaksanakan tugasnya sesuai dengan tanggung jawab yang diberikan kepadanya. Menurut Gomes (2002:142) menyatakan bahwa kriteria pengukuran kinerja berdasarkan prilaku yang spesifik adalah sebagai berikut :

1. Quantity of work, yaitu jumlah tenaga kerja yang dilakukan dalam suatu periode tertentu.

2. Quality of work, yaitu kualitas kerja yang dicapai berdasarkan syarat-syarat kesiapannya.

3. Job knowledge, yaitu luasnya pengetahuan mengenai pekerjaan dan keterampilannya.

4. Creativeness, yaitu keaslian gagasan yang dimunculkan dan tindakan untuk menyelesaikan persoalan-persoalan yang timbul.

5. Cooperation, yaitu kesediaan untuk bekerja sama dengan orang lain (sesama anggota organisasi). 
6. Dependability, yaitu kesadaran berdisiplin dan dapat dipercaya dalam kehadiran dan penyelesaian pekerjaan.

7. Initiative, yaitu semuanya untuk melaksanakan tugas-tugas baru dan dalam memperbesar tanggung jawabnya.

8. Personal qualities, yaitu menyangkut kepribadian, kepemimpinan, keramahtamahan, dan integritas pribadi.

Kualitas layanan adalah persepsi pelanggan terhadap keseluruhan kualitas atau keunggulan suatu produk atau jasa layanan berkenaan dengan maksud yang diharapkan. Penelitian ini sebelumnya dilakukan oleh Domases Al Atak (2009) tentang motivasi terhadap peningkatan kinerja, menunjukkan motivasi berpengaruh secara signifikan terhadap kinerja.

Menurut Indah Susanti (2005) tentang pengaruh motivasi terhadap prestasi kerja, menunjukkan bawah motivasi berpengaruh secara signifikan terhadap prestasi kerja. Penelitian Indah (2001) menemukan bahwa motivasi kerja dan prestasi kerja karyawan dapat diketahui rata-rata karyawan sudah termotivasi untuk berprestasi dalam melaksanakan tugas yang dibebankan. Motivasi kerja karyawan berpengaruh signifikan terhadap prestasi kerja karyawan.

\section{Metode Penelitian}

Penelitian ini menggunkana metode "Cross Sectional" untuk melakukan penjelasan keadaan saat itu, sehingga dari data yang diperoleh dapat menjelaskan ada tidaknya hubungan kausal antar variabel. Penelitian dilakukan di Rumah makan Wong Solo. Jumlah populasi yang diambil untuk menentukan ukuran sampel ialah konsumen yang berkunjung pada tahun 2013, sesuai dengan sumber Rumah makian Wong Solo tahun 2013. Penelitian ini membatasi jumlah sampel menjadi 100 responden. Variabel yang digunakan dalam penelitian yaitu motivasi, kompetensi, kinerja dan kualitas layanan. Alat analisis yang digunakan adalah analisis jalur.

\section{Tabel 2. Rekapitulasi Tanggapan Responden atas Variabel Motivasi}

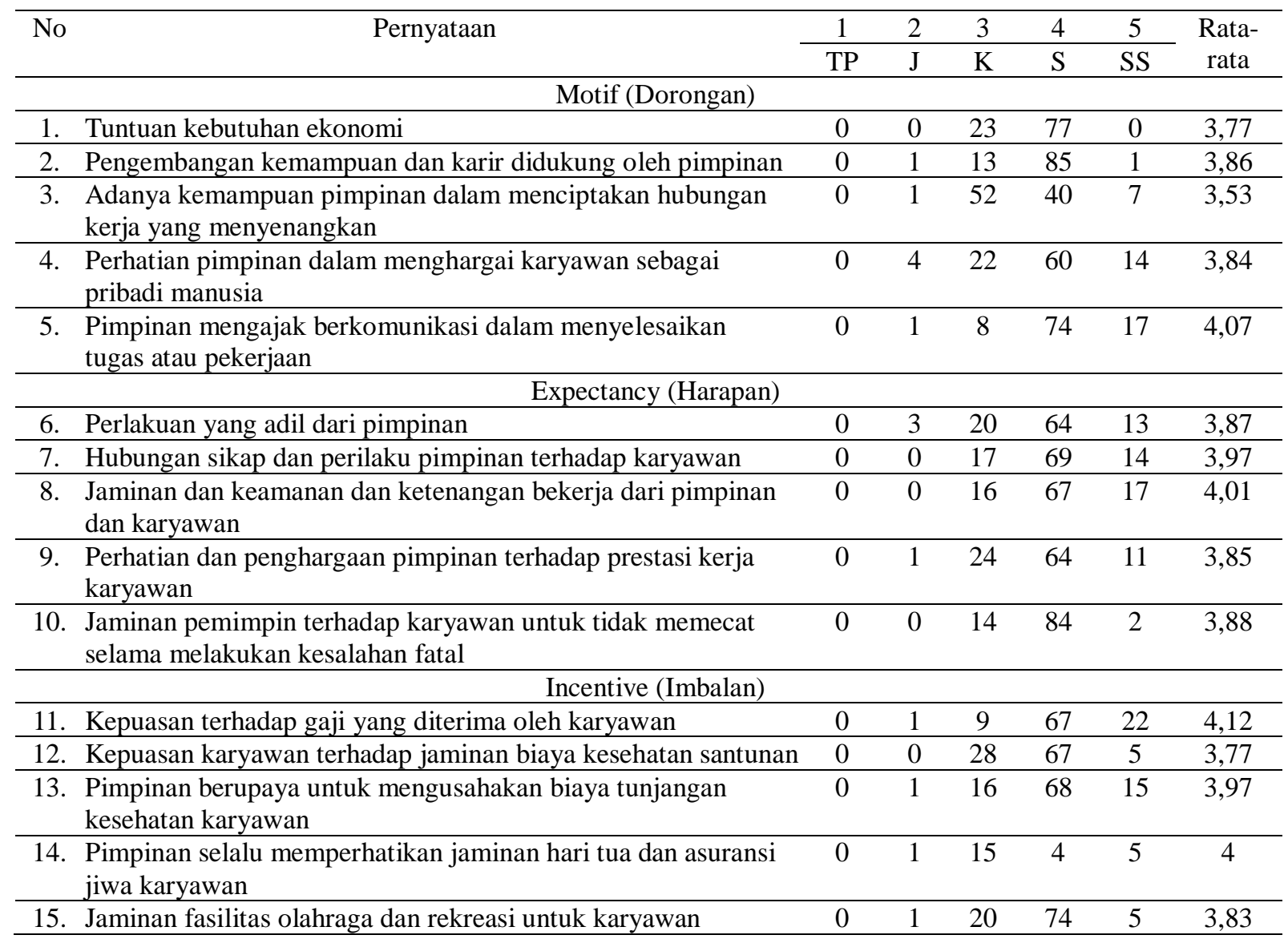


Tabel 3. Rekapitulasi Tanggapan Responden atas Variabel Kompetensi

\begin{tabular}{|c|c|c|c|c|c|c|c|}
\hline \multirow[t]{2}{*}{ No } & \multirow[t]{2}{*}{ Pernyataan } & 1 & 2 & 3 & 4 & 5 & \multirow{2}{*}{$\begin{array}{l}\text { Rata } \\
\text {-rata }\end{array}$} \\
\hline & & $\mathrm{TP}$ & $\mathrm{J}$ & $\mathrm{K}$ & $\mathrm{S}$ & SS & \\
\hline \multicolumn{8}{|c|}{$\begin{array}{ll} & \text { Pengetahuan } \\
\end{array}$} \\
\hline & $\begin{array}{l}\text { Informasi yang karyawan miliki sudah sesuai dengan pekerjaan } \\
\text { yang karyawan kerjakan }\end{array}$ & 0 & 2 & 50 & 43 & 5 & 3,5 \\
\hline \multicolumn{8}{|c|}{ Keterampilan } \\
\hline & $\begin{array}{l}\text { Kemampuan yang karyawan miliki sudah siap dengan fisik dan } \\
\text { mental dengan pekerjaan yang karyawan kerjakan }\end{array}$ & 0 & 2 & 16 & 79 & 3 & 3,83 \\
\hline \multicolumn{8}{|c|}{ Perangai/Sifat } \\
\hline & $\begin{array}{l}\text { Karakteristik dan tanggapan karyawan sudah konsisten terhadap } \\
\text { informasi atau situasi pekerjaan yang karyawan kerjakan }\end{array}$ & 0 & 1 & 16 & 72 & 11 & 3,93 \\
\hline \multicolumn{8}{|c|}{ Konsep Diri } \\
\hline & $\begin{array}{l}\text { Sikap, nilai atau image diri, penting terhadap apa yang karyawan } \\
\text { kerjakan }\end{array}$ & 0 & 1 & 17 & 63 & 19 & 4 \\
\hline & Jaminan fasilitas olahraga dan rekreasi untuk karyawan & 0 & 1 & 20 & 74 & 5 & 3,83 \\
\hline
\end{tabular}

Tabel 4. Rekapitulasi Tanggapan Responden atas Variabel Kinerja

\begin{tabular}{|c|c|c|c|c|c|c|c|}
\hline \multirow[t]{2}{*}{ No } & \multirow[t]{2}{*}{ Pernyataan } & 1 & 2 & 3 & 4 & 5 & \multirow{2}{*}{$\begin{array}{l}\text { Rata } \\
\text {-rata }\end{array}$} \\
\hline & & $\mathrm{TP}$ & $\mathrm{J}$ & $\mathrm{K}$ & $\mathrm{S}$ & $\mathrm{SS}$ & \\
\hline \multicolumn{8}{|c|}{ Quantity of Work } \\
\hline & $\begin{array}{l}\text { Jumlah tenaga kerja yang dilakukan dalam suatu periode waktu } \\
\text { tertentu }\end{array}$ & 0 & 2 & 44 & 50 & 4 & 3,56 \\
\hline \multicolumn{8}{|c|}{ Quality of Work } \\
\hline 2. & Kualitas kerja yang dicapai berdasarkan syarat-syarat kesiapannya & 0 & 2 & 17 & 79 & 2 & 3,81 \\
\hline \multicolumn{8}{|c|}{ Job Knowledge } \\
\hline 3. & Luasnya pengetahuan mengenai pekerjaan dan keterampilannya & 0 & 2 & 15 & 67 & 16 & 3,97 \\
\hline \multicolumn{8}{|c|}{ Creativeness } \\
\hline & $\begin{array}{l}\text { Keaslian gagasan yang dimunculkan dan tindakan untuk } \\
\text { menyelesaikan persoalan-persoalan yang timbul }\end{array}$ & 0 & 0 & 37 & 61 & 2 & 3,65 \\
\hline \multicolumn{8}{|c|}{ Cooperation } \\
\hline & Kesediaan untuk bekerjasama dengan orang lain & 0 & 0 & 12 & 86 & 2 & 3,9 \\
\hline \multicolumn{8}{|c|}{ Dependability } \\
\hline & $\begin{array}{l}\text { Kesadaran berdisiplin dan dapat dipercaya dalam kehadiran dan } \\
\text { penyelesaian pekerjaan }\end{array}$ & 0 & 3 & 22 & 61 & 14 & 3,86 \\
\hline \multicolumn{8}{|c|}{ Initiative } \\
\hline 7. & $\begin{array}{l}\text { Semangat untuk melaksanakan tugas-tugas baru dan dalam } \\
\text { memperbesar tanggung jawabnnya }\end{array}$ & 0 & 0 & 8 & 71 & 21 & 4,13 \\
\hline \multicolumn{8}{|c|}{ Personal Qualities } \\
\hline & $\begin{array}{l}\text { Menyangkut kepribadian, kepemimpinan, keramahtamahan dan } \\
\text { integritas pribadi }\end{array}$ & 0 & 5 & 20 & 63 & 12 & 3,82 \\
\hline
\end{tabular}

\section{Hasil Penelitian Dan Pembahasan}

Penelitian dilakukan dengan jumlah responden sebesar 100 orang (pengunjung rumah makan). Analisis data dimulai dengan melakukan uji validitas dan reliabilitas instrumen. Hasil pengujian menunjukkan bahwa semua data yang digunakan dalam penelitian ini dinyatakan valid dan reliabel. Ini artinya data yang digunakan dalam penelitian ini tidak bermakna ganda, dan sesuai dengan apa yang ingin diukur.

Hasil deskripsi variabel menunjukkan bahwa pada Rumah Makan Wong Solo, karyawannya pada saat ini memiliki tingkat motivasi, kompetensi, kinerja, dan kualitas pelayanan yang diatas rata-rata, dimana ratarata penilaian untuk masing-masing variabel menunjukkan nilai diatas 3 . Temuan awal ini memperkuat dugaan bahwa dengan motivasi dan kompetensi yang baik, kinerja karaywan akan terus terjaga dan akhirnya kualias pelayanan juga akan baik, selengkapnya dapat dilihat pada Tabel 2, 3, dan 4.

Langkah selanjutnya adalah melakukan serangkaian analisis regresi berganda untuk membentuk suatu analisis jalur. Proses 
analisis dilakukan pertama kali dengan cara mencari koefisien regresi dari pengaruh motivasi dan kompetensi terhadap kinerja pada Rumah Makan Wong Solo. Setelah itu, dilanjutkan dengan membuat pengujian yang kedua, yaiu mencari pengaruh dari motivasi, kompetensi, dan kinerja terhadap kepuasan pelayanan di Rumah Makan Wong Solo.

Setelah serangkaian analisis dilakukan, ditemukan serangkaian hasil penelitian sebagai berikut:

1. Dilihat dari sudut pandang parsial, berdasarkan uji t diketahui bahwa untuk motivasi thitung $=15,517^{* *}$ (sangat signifikan), artinya secara parsial motivasi dapat mempengaruhi secara langsung kinerja karyawan Rumah Makan Ayam Bakar Wong Solo.

2. Dilihat dari sudut pandang parsial, berdasarkan uji t diketahui bahwa untuk kompetensi $t_{\text {hitung }}=10,625^{* *}$ (sangat signifikan), artinya kompetensi dapat mempengaruhi secara langsung kinerja karyawan Rumah Makan Ayam Bakar Wong Solo.

3. Di luar dari sudut pandang parsial, berdasarkan uji t diketahui bahwa untuk motivasi thitung $=13,579^{* *}$ (sangat signifikan) artinya motivasi dapat mempengaruhi secara langsung kualitas layanan Rumah Makan Ayam Bakar Wong Solo.

4. Dilihat dari sudut pandang parsial, berdasarkan uji t diketahui bahwa untuk kompetensi $t_{\text {hitung }}=12,397^{* *}$ (sangat signifikan) artinya kompetensi dapat mempengaruhi secara langsung kualitas layanan Rumah Makan Ayam Bakar Wong Solo.

5. Dilihat dari sudut pandang simultan berdasarkan uji t diketahui bahwa untuk motivasi $t_{\text {hitung }}=4,107^{* * *}$ (sangat signifikan) sedangkan untuk kompetensi $t_{\text {hitung }}=-0,014^{\text {ns }} \quad$ (tidak signifikan) walaupun demikian secara kualitas layanan Rumah Makan Ayam Bakar Wong Solo untuk harga koefisien jalur motivasi dan kompetensi terhadap kinerja adalah sebagai berikut: coefesien motivasi $\left(\mathrm{X}_{1}\right)$ menjadi 0,734 , kompetensi $\left(\mathrm{X}_{2}\right)$ menjadi 0,134 . $\mathrm{R}$ Square $=0,717$, dengan demikian koefesien jalur $\in$ (variabel di luar model) adalah :

$Y_{1} \in=\sqrt{1-0,717=0,283}$

Dari kedua variabel motivasi dan kompetensi secara simultan yang dominan berpengaruh langsung terhadap kinerja karyawan adalah variabel motivasi sebesar 0,538 sedangkan kompetensi pengaruhnya sangat kecil yaitu 0,017 .

6. Untuk harga koefesien jalur motivasi dan kompetensi terhadap kualitas layanan melalui variabel intervening kinerja adalah sebagai berikut: Motivasi $\left(\mathrm{X}_{1}\right)$ menjadi 0,626, Kompetensi $\left(\mathrm{X}_{2}\right)$ menjadi 0,002 , koefesien Kinerja $\left(\mathrm{Y}_{1}\right)$ menjadi $0,241, \mathrm{R}$ Square $=0,688$. Dengan demikian koefesien jalur $\in$ (variabel di luar model) adalah :

$Y_{1} \in=\sqrt{1-0,688=0,1558}$

Dari kedua variabel motivasi dan kompetensi secara simultan yang dominan berpengaruh langsung terhadap kualitas layanan melalui variabel intervening kinerja karyawan adalah variabel motivasi sebsar 0,05025, sedangkan kompetensi pengaruhnya sangat kecil yaitu 0,000004 . Artinya jalur yang lebih dekat adalah melalui variabel motivasi untuk mempengaruhi kualitas layanan melalui variabel intervening kinerja.

Temuan-temuan ini membuktikan
bahwa motivasi dan kompetensi
mempengaruhi kualitas pelayanan di Rumah
Makan Ayam Bakar Wong Solo, baik secara
langsung, maupun secara tidak langsung
melalui variabel kinerja. Ini artinya, untuk
menciptakan pelayanan yang berkualitas,
Rumah Makan Wong Solo harus terus
menjaga motivasi kerja dari para
pegawainya. Selain ini, Rumah Makan Wong
Solo juga harus terus meningkatkan
kompetensi dari karyawannya agar
kinerjanya selalu baik dan akhirnya tercipta
pelayanan yang berkualitas.

Temuan-temuan ini membuktikan bahwa motivasi dan competensi mempengaruhi kualitas pelayanan di Rumah Makan Ayam Bakar Wong Solo, baik secara langsung, maupun secara tidak langsung melalui variabel kinerja. Ini artinya, untuk menciptakan pelayanan yang berkualitas, Rumah Makan Wong Solo harus terus menjaga motivasi kerja dari para pegawainya. Selain ini, Rumah Makan Wong Solo juga harus terus meningkatkan kompetensi dari karyawannya agar pelayanan yang berkualitas. 


\section{Kesimpulan}

Berdasarkan hasil penelitian ini dapat disimpulkan hal-hal sebagai berikut:

1. Motivasi dan kompetensi sama-sama mempengaruhi kinerja karyawan di Rumah Makan Wong Solo

2. Motivasi dan kompetensi sama-sama mempengaruhi kualitas pelayanan di Rumah Makan Wong Solo

3. Kinerja mempengaruhi kualitas pelayanan di Rumah Makan Wong Solo

\section{DAFTAR PUSTAKA}

Alfani, Muhammad. 2010. Filsafat Ilmu dan Metodologi Penelitian. Cetakan Ketujuh. Adi Primajaya Komputer. Banjarmasin.

Anwar Prabu Mangkunegara. 2006. Manajemen Sumber Daya Manusia Perusahaan. Cetakan Keenam. PT. Remaja Rosdakarya. Bandung.

Arikunto, Suharsimi. 2006. Prosedur Penelitian Suatu Pendekatan Praktik. Jakarta: Rineka Cipta.
Cribbin, J.J. 1985. Kepemimpinan Strategi Mengefektifkan Organisasi. PT. Pustaka Binama Pressindo. Jakarta.

Hasibuan, Malayu SP. 2001. Manajemen Sumber Daya Dasar dan Kunci Keberhasilan (Edisi Revisi). Cetakan Ketiga. PT. Bumi Aksara, Jakarta.

Gibson, L. James, Donelly Jr. H. James and Ivansevich M. Jhon. 2001. Fundamental of Management. Eight, Richard D, Irwin Inc, New York.

Gomes, Cardoso Fanstino. 1997. Manajemen Sumber Daya Manusia. Edisi Pertama, Cetakan Kedua. Andi Offset, Yogyakarta.

Supriyatmi, T.S. 2005. Kualitas Pelayanan Terhadap Loyalitas Nasabah. Semarang: Universitas Negeri Semarang.

Lupiyoadi, R. 2001. Manajemen Pemasaran Jasa. Jakarta: PT. Salemba Empat.

Manullang M dan Manullang AMH Marihot. 2004. Manajemen Personalia. Gajah Mada University Press, Yogyakarta. 